\title{
Temporal Energy Restriction and the Timing of Vaginal Opening in Female Rats
}

\author{
Kazuyoshi HASHIZUME* and Kiyotaka OHASHI \\ Center for Laboratory Animal Science, National Defense \\ Medical College, 3-2 Namiki Tokorozawa, Saitama 359, Japan
}

\begin{abstract}
The effect of a temporary dietary restriction ( $10 \mathrm{~g} /$ day) duirng gestation or lactation on the subsequent maturation of female offspring was examined. Mother rats were divided into 6 groups according to the period of restriction: namely, Group A (between days 0 and 7 of gestation), Group B (between days 8-14 of gestation), Group C (between days 15-21 of gestation), Group D (between days 1-7 of lactation), Groupt $\mathrm{E}$ (between days 8-14 of lactation), Group F (no restriction). In Group E, the mother's body weight decreased by $17 \%$ compared to that on day 0 of gestation. Female pups in this group showed retardation in growth rate concurrent with a delay in vaginal opening. No significant effects were found in any other groups. These results suggest that adequate nutrition during midlactation is critical for optimal growth of female pups and subsequent opening of the vagina.
\end{abstract}

Key words: Pup growth, Energy restriction, Vaginal opening.

(J. Reprod. Dev. 41: 225-228, 1995)

$\mathbf{R}$ ats reach sexual maturity at about 5 weeks of age; however, this is dependent on a combination of environmental and genetic factors. The effect of nutrition level on the attainment of puberty and the relationship between body weight and vaginal opening in the rat is substantial and well documented [1-3]. Most earlier studies that describe the association between nutrition and the attainment of sexual maturity based their conclusions on post-weaning investigations or long-term food restriction [4-7]. However, the effect of provisional changes in nutritional status duirng gestation and/or lactation on the attainment of puberty in the pups remains ill-defined.

We hypothesized [8-9] that variations in the timing of first estrus among female litter mates may

Accepted for publication: Feburary 28, 1995

Correspondence: K. Hashizume

* Present address: Laboratory of Female Reproductive Endocrinology, National Institute of Animal Industry, Norindanchi P.O.Box 5, Tsukuba, Ibaraki 305, Japan be caused by a temporal change in food ration at certain periods during gestation or lactation. In the present study, we evaluated the effect of a temporary reduction in the mother's food ration during gestation or lactation and its subsequent influence on sexual maturation of the offspring.

\section{Materials and Methods}

Wistar-Imamichi rats were housed at a controlled temperature (22-24 C) with a light period or $14 \mathrm{~h} /$ day (lights on at 05:00 h). They were allowed free access to commercial rat chow consisting of $24.8 \%$ crude protein, $4.4 \%$ fat and $3.5 \%$ fiber with a caloric value of $345.2 \mathrm{Cal} / 100 \mathrm{~g}$ (CE2, CLEA-JAPAN, Tokyo).

The day sperm was detected in the vaginal smear was defined as day 0 of pregnancy. Pregnant rats were checked at 09:00 h on day 21 and 22 of pregnancy, and the day when all pups appeared was 
designated as the day of delivery (day 1 of lactation and day 1 of age for pups). Body weights of the mother and pups were individiually monitored. After 28 days of age, female pups were checked for vaginal opening at 09:00 h every morning. Ovulation was checked on the day of vaginal opening. The number of ova in the fallopian tubes was counted under a microscope. In the case of male pups, only the body weight was assessed from birth to 42 days of age.

Dams were restricted to $10 \mathrm{~g} /$ day of chow from days 0 to 7 of gestation (Group $A, n=5$ ), from days 8 to 14 of gestation (Group B, $n=4$ ), from days 15 to 21 of gestation (Group $C, n=4$ ), from days 1 to 7 of lactation (Group D, n=7), or from days 8 to 14 of lactation (Group $\mathrm{E}, \mathrm{n}=7$ ). A group without dietary restriction served as a control (Group $\mathrm{F}, \mathrm{n}=10$ ). During the period of restriction, dams in groups $\mathrm{A}$ to $\mathrm{E}$ were fed $45,40,38,35$ and $18 \%$, respectively, of the control. All groups were fed ad libitum except during the restriction period. The restriction diet (about $10 \mathrm{~g} /$ day $/$ rat) was determined in a preliminary study as the quantity of chow that non-pregnant female rats (10 weeks of age) needed to maintain their body weight for at least one week. The number of pups was adjusted to 8 (4 males and 4 females) by random culling at deliv- ery.

Statistical analyses were performed by 1-way analysis of variances and Duncan's multiple range test for body weight changes on each weighing day. Differences in the onset of puberty (vaginal opening) were assessed with the Mann-Whitney U-test.

\section{Results}

Body weight changes in dams duirng gestation and lactation are shown in Fig. 1. The body weight of intact mothers compared to day 0 of gestation (weight on day 0 was referenced as 100\%) increased to $160 \%$ during gestation, then declined to $110 \%$ after delivery, and reached $130 \%$ by day 21 of lactation. The body weight of dams in Group E decreased during the restriction period by $17 \%$ compared to that on day 0 of gestation. In Group $\mathrm{D}$, maternal body weight decreased by $13 \%$ compared day 0 of gestation; however, in Groups A, B and $C$ with dietary restrictions during gestation, body weights were 94,103 and $126 \%$, respectively.

The mean $( \pm$ SEM) food intake of dams during gestation and lactation is shown in Table 1. Although the restricted groups received only $70 \mathrm{~g}$ of

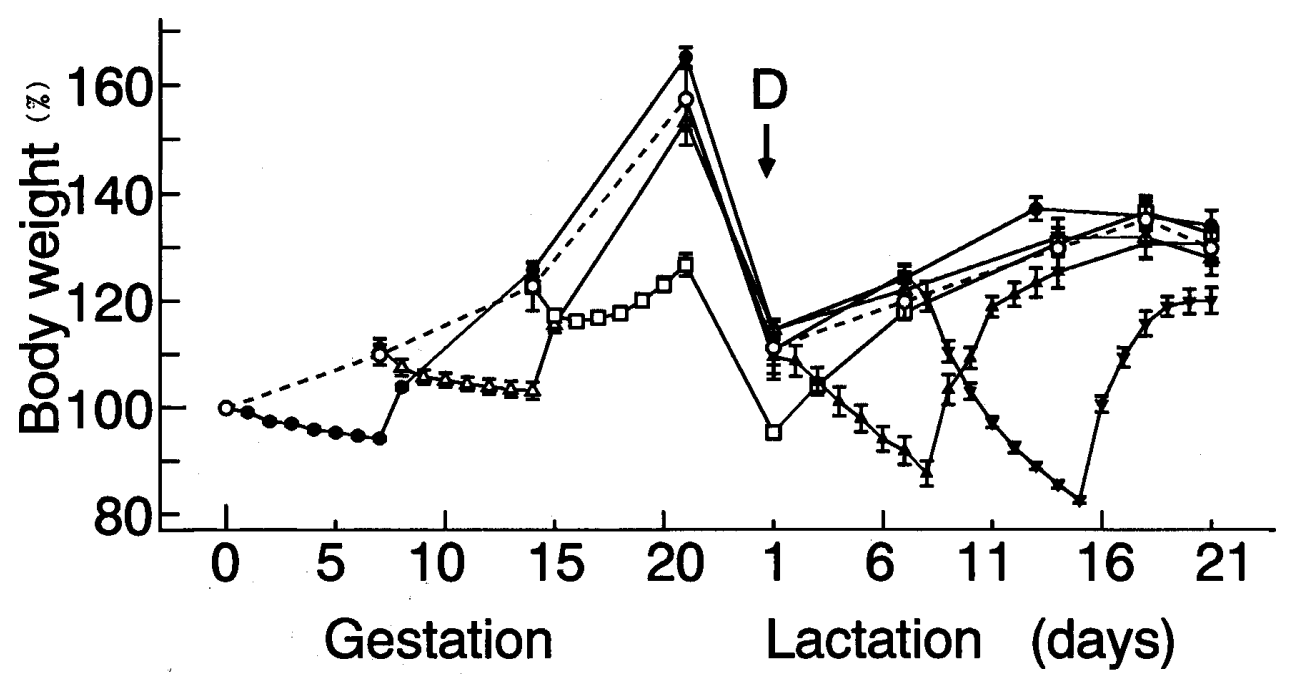

Fig. 1. Effects of food restriction during gestation and lactation on maternal body weight. Dams were fed only $10 \mathrm{~g} /$ day during the following period: Group A ( days 0-7 of pregnancy, $n=5)$, Group B $(\triangle$, days 8-14 of pregnancy $n=4)$, Group $C(\square$, days 1521 of pregnancy, $n=4)$, Group D $(\boldsymbol{\Lambda}$, days 1-7 of lactation, $n=7)$, and Group $E(\boldsymbol{\nabla}$, days 8-14 of lactation, $\mathrm{n}=7)$, Group $\mathrm{F}(\bigcirc, \mathrm{n}=10)$ received an unrestricted diet as a control. Data are shown as a ratio of body weight on day 0 of gestation in the control in the control group (Group F) referenced to $100 \%$. 
Table 1. Changes in food intake during restriction periods

\begin{tabular}{|c|c|c|c|c|c|c|c|}
\hline \multirow[t]{2}{*}{ Group } & \multicolumn{3}{|c|}{ period of gestation } & \multicolumn{3}{|c|}{ period of lactation } & \multirow[t]{2}{*}{ Total } \\
\hline & $0-7$ & 8-14 & $15-21$ & $1-7$ & 8-14 & $15-21$ & \\
\hline A ( 5)\# & $71.1 \pm 0.1^{* *}$ & $216.9 \pm 2.4^{* *}$ & $223.5 \pm 4.6^{* *}$ & $245.3 \pm 9.8^{* *}$ & $436.5 \pm 10.6^{* *}$ & $498.2 \pm 14.0$ & $1691.2 \pm 16.7$ \\
\hline B ( 4$)$ & ND & $71.9 \pm 0.3^{* *}$ & $236.7 \pm 9.4^{* *}$ & $220.5 \pm 11.5^{* *}$ & $424.5 \pm 16.8^{* *}$ & $483.6 \pm 11.2$ & $1594.4 \pm 27.9$ \\
\hline$C(4)$ & ND & ND & $72.8 \pm 0.6^{* *}$ & $262.6 \pm 17.0^{* *}$ & $431.8 \pm 23.4^{* *}$ & $485.8 \pm 21.9$ & $1590.8 \pm 56.8$ \\
\hline $\mathrm{D}(7)$ & ND & ND & ND & $72.7 \pm 0.5^{* *}$ & $390.9 \pm 14.7$ & $518.9 \pm 7.4$ & $1514.6 \pm 17.6^{*}$ \\
\hline $\mathrm{E}(7)$ & ND & ND & ND & ND & $70.8 \pm 0.2^{* *}$ & $432.2 \pm 21.2$ & $1241.0 \pm 25.8^{* *}$ \\
\hline F (10) & $157.0 \pm 7.1$ & $181.3 \pm 9.6$ & $194.0 \pm 7.7$ & $207.8 \pm 8.1$ & $399.6 \pm 27.2$ & $485.6 \pm 14.8$ & $1626.0 \pm 47.4$ \\
\hline
\end{tabular}

Data are presented as means \pm SEM $(\mathrm{g})$.

\#Capital letters show restriction periods: $A=$ day $0-7$ of gestation, $B=$ day $8-14$ of gestation, $C=$ day $15-21$ of gestation, $\mathrm{D}=$ day $1-$ 7 of lactation, $E=$ day $8-14$ of lactation, $F=$ no restriction. ND: Not determined. Number in parentheses indicates the number of dams.

The amount of total food intake in Group B to E before restriction were calculated from that of the control (Group F).

${ }^{*}, \mathrm{P}<0.05:{ }^{* *}, \mathrm{P}, 0.01$ : Significantly different from the control (Group F).

Table 2. Effect of maternal dietary restriction during gestation or lactation on the timing of vaginal opening in female offspring

\begin{tabular}{lcclcc}
\hline Group & No. dams & Day of V.O. & BW at open & No. ova & Ratio \\
\hline A\# & 5 & $33.8 \pm 0.5$ & $122.2 \pm 3.3$ & $13.0 \pm 0.1$ & $19 / 20$ \\
B & 4 & $34.4 \pm 0.4$ & $125.1 \pm 2.3$ & $11.9 \pm 0.3$ & $16 / 16$ \\
C & 4 & $33.4 \pm 0.5$ & $119.6 \pm 2.5$ & $11.4 \pm 0.5$ & $16 / 16$ \\
D & 7 & $32.7 \pm 0.6$ & $114.4 \pm 2.5$ & $12.2 \pm 0.2$ & $26 / 28$ \\
E & 7 & $35.0 \pm 0.4^{*}$ & $111.0 \pm 2.8^{* *}$ & $12.3 \pm 0.2$ & $25 / 28$ \\
F & 10 & $33.5 \pm 0.3$ & $119.2 \pm 3.7$ & $12.0 \pm 0.2$ & $38 / 40$ \\
\hline
\end{tabular}

\#Capital letters show restriction periods: $\mathrm{A}=$ day $0-7$ of gestation, $\mathrm{B}=$ day $8-14$ of gestation, $\mathrm{C}=$ day $15-21$ of gestation, $\mathrm{D}=$ day $1-7$ of lactation, $\mathrm{E}=$ day $8-14$ of lactation, $\mathrm{F}=$ no restriction. V.O.: vaginal opening, B.W.: body weight, No. ova: average ovulations per pup, and ratio: ovulating female pups per pups examined on vaginal opening day.

Data show average per dam (mean \pm SEM) except ovulation ratio.

${ }^{*}, \mathrm{P}<0.05:{ }^{* *}, \mathrm{P}<0.01$ : Significantly different from the control (Group F).

chow during their respective restriction periods, total food intake in Groups A-C was almost the same as in Group F.

Dietary restriction during gestation (Groups AC) had no effect on the length of the gestation period, the number of live pups born or on the body weight of the pups on the day of delivery (data not shown). When dams were given a restricted diet on days 8-14 of lactation (Group E), their offspring showed a retardation in growth and a delay in the time of vaginal opening (Table 2). Their body weight did not catch up with that of the other groups until puberty $(\mathrm{P}<0.01$, Fig. 2$)$. However, no difference was noted in the ovulation rate or the number of ova in any of the groups.

Male pups showed a very similar growth pattern to that of females; however, the males in Group E gained only $177.8 \pm 2.3 \mathrm{~g}$ (Mean \pm SEM, $\mathrm{n}=7$ ) by day 42 . This value was significantly lower com- pared to that of Group F $(199.9 \pm 6.0, n=10, P<0.01)$.

\section{Discussion}

Many previous studies applied longer periods of food deprivation, i.e. the entire gestation and/ or lactation period and over $50 \%$ restriction of the counterpart. They showed not only significant changes in maternal carcass composition but also demonstrated arrested growth in the offspring. These effects were found after food restriction during gestation as well as lactation [7, 10-12]. Shorter periods of restriction employed in the present study provide a better means of identifying the critical period during the growth phase and the subsequent requirement of optimum nutrition. Our result showed that only restriction during the 2nd week of lactation retarded growth of the pups and 


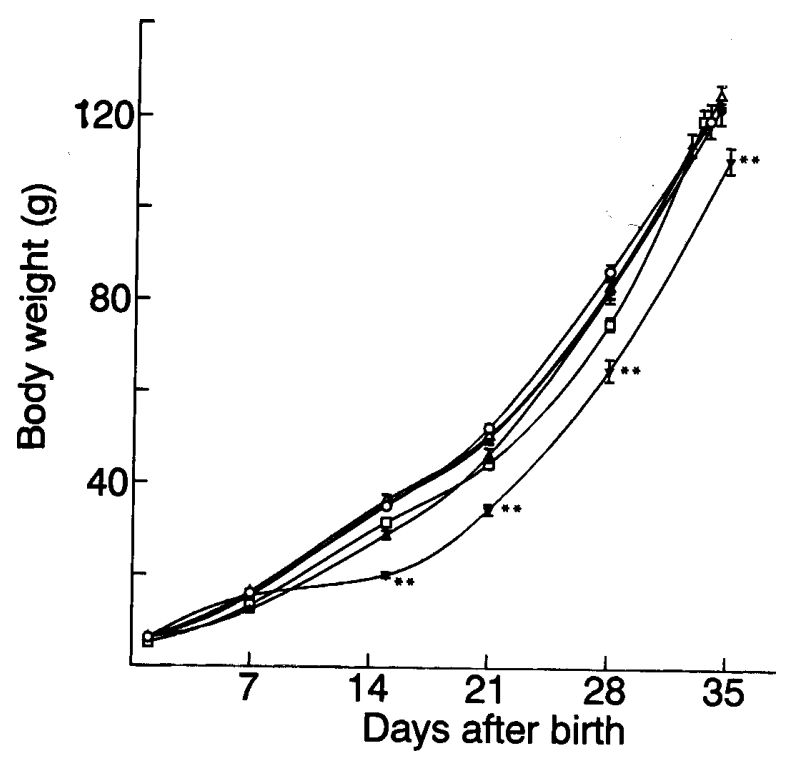

delayed the opening of the vagina. However, restriction duirng pregnancy had less effect because nutrients seem to be easily mobilized during gestation [11]. We did not examine the effect of food restriction on the growth of pups and subsequent time of vaginal opening during the 3rd week of lactation because the pups are known to take sol-
Fig. 2. Effects of maternal dietary restriction on the growth of female pups. Body weight changes of female rat pups are shown. Dams were fed a restricted diet during the following periods: Group A $(\mathbf{O}$, days 0 7 of pregnancy, $n=5)$, Group B $(\triangle$, days $8-14$ of pregnancy, $n=4)$, Group $C(\square$, days 15-21 of pregnancy, $n=4)$, Group $D(\boldsymbol{\Delta}$, days $1-7$ of lactation, $\mathrm{n}=7)$, and Group $\mathrm{E}(\boldsymbol{\nabla}$, days 8-14 of lactation, $\mathrm{n}=7$ ). Group $\mathrm{F}(\bigcirc, \mathrm{n}=10)$ received and unrestricted diet as a control. Data are shown from day 1 (birth) to vaginal opening. Values are the mean \pm SEM. ${ }^{* *}$ Significant difference from Group $\mathrm{F}(\mathrm{P}<0.01)$.

ids from the third week onwards $[13,14]$.

These results suggest that adequate nutrition during mid-lactation is critical for the optimum growth of the pups and subsequent opening of the vagina. However, further studies are needed to clarify the relationship between nutritional status during mid-lactation and the maturation of hypothalamic-pituitary-gonadal function.

\section{Acknowledgment}

The authors thank Osman Patel for helpful discussion and advice on the manuscript.

\section{References}

1. Kennedy GC, Mitra J. Body weight and food intake as initiating factors for puberty in the rat. $J$ Physiol 1963; 166: 408-418.

2. Frisch RE, Hegsted DM, Yoshinaga K. Body weight and food intake at early estrus of rats on a high-fat diet. Proc Natil Acad Sci USA 1975; 72: 4172-4176.

3. Lintern-Moore S, Everitt AV. The effects of restricted food intake on the size and composition of the ovarian follicle population in the Wistar rat. Biol Reprod 1978; 19: 688-691.

4. Slob AK, van Es G, van der Werff ten Bosch JJ. Social factors and puberty in female rats. J Endocr 1985; 104: 309-313.

5. Nelson JF, Karelus K, Felicio LS, Johnson TE. Genetic influences on the timing of puberty in mice. Biol Reprod 1990; 42: 649-655.

6. Blake $\mathbf{H H}$, Henning SJ. Weaning in the rat: a study of hormonal influences . Am J Physiol 1983; 244: R537-543.

7. Rasmussen KM, Warman NL. Effect of maternal malnutrition during the reproductive cycle on growth and nutritional status of suckling rat pups. Am J Clin Nutr 1983; 38: 77-83.

8. Hashizume K, Ohashi K, Hamajima F. Adoles- cent pregnancy and growth of progeny in rats. Physiol Behav 1991; 49: 367-371.

9. Arts CJM, Govers CARL, van den Berg $\mathbf{H}$, Thijssen JHH. Effects of wheat bran and energy restriction on onset of puberty, cell proliferation and development of mammary tissue in female rats. Acta Endocrinol 1992; 126: 451-459.

10. Hsueh AM, Siomnson M, Chow BF, Hanson HM. The importance of the period of dietary restriction of the dam on behavior and growth in the rat. $J$ Nutr 1974; 104: 37-46.

11. Leon M, Woodside B. Energetic limits on reproduction: Maternal food intake. Physiol Behav 1983; 30: 945-957.

12. Forsberg G, Abrahamsson K, Sodersten P, Eneroth P. Effects of restricted maternal contact in neonatal rats on sexual behaviour in the adult. $J$ Endocr 1985; 104: 427-431.

13. Redman RS, Sweney LR. Changes in diet and patterns of feeding activity of developing rats. J Nutr 1976; 106: 615-626.

14. Henning SJ, Chang SP, Gisel EG. Ontogeny of feeding controls in suckling and weaning rats. Am J Physiol 1979; 237: R187-191. 